\title{
CHANGES IN EXTREME TEMPERATURE EVENTS AND THEIR RELATIONSHIPS WITH THE EL NIÑO-SOUTHERN OSCILLATION IN THE WEI RIVER BASIN, CHINA
}

\author{
YAN, D. F. ${ }^{1}-$ JIANG, R. G. ${ }^{1,2^{*}}-$ XIE, J. C. ${ }^{1 *}-$ ZHAO, Y. ${ }^{3}$ - LIANG, J. C. ${ }^{1}-$ WANG, Y. P. ${ }^{1}$ \\ ${ }^{1}$ State Key Laboratory of Eco-hydraulics in Northwest Arid Region of China, Xi'an University \\ of Technology, Xi'an 710048, China \\ ${ }^{2}$ Department of Geography, National University of Singapore, Kent Ridge 117570, Singapore \\ ${ }^{3}$ State Key Laboratory of Simulation and Regulation of Water Cycle in River Basin, China \\ Institute of Water Resources and Hydropower Research, Beijing 100038, China \\ ${ }^{*}$ Corresponding authors \\ e-mail:jrengui@163.com; jcxie@xaut.edu.cn \\ (Received $12^{\text {th }}$ Nov 2019; accepted $12^{\text {th }}$ Feb 2020)
}

\begin{abstract}
Extreme temperature indices (ETIs) are used to assess extreme temperature events, to further reveal possible climate impacts of El Niño-Southern Oscillation (ENSO) on temperature extremes. The primary objective of this paper is to investigate the spatial and temporal variability of ETIs, and further examine the linear and nonlinear relationships between ETIs and two ENSO anomalies including the Niño 3.4 and Southern Oscillation Index (SOI) between 1969 and 2016 in the Wei River Basin (WRB) of China. The trends of ETIs were analyzed using Mann-Kendall test and cloud model, and the relationships between ENSO and ETIs were quantified using correlation and wavelet analysis. Results showed that the ETIs had increased from 1969 to 2016. Most of the stations exhibited similar trends for each ETIs except diurnal temperature range (DTR). The trend of minimum temperature (Tmin) was larger than that of maximum temperature (Tmax). Meanwhile, the variability of Tmin in the south of WRB was more stable than in other regions. Niño 3.4 was mainly positively correlated with PC1 of ETIs, and vice versa for SOI. The results help to understand the changes in extreme temperature events and their relationships with climate anomalies, which can provide scientific references for the water resource management of the watershed.
\end{abstract}

Keywords: extreme temperature events, linear and nonlinear relationships, cross wavelet analysis, trend analysis, cloud model, Wei River Basin

\section{Introduction}

According to the fifth Assessment Report (AR5) of Intergovernmental Panel on Climate Change (IPCC), surface air temperature had increased for past several decades, especially since 1850 . In addition to the conclusive multi-decadal warming, the global average surface temperature showed obvious inter-decadal and inter-annual variations (IPCC, 2014). The frequency and magnitude of extreme climate events had significantly increased around the world (Utsumi et al., 2011; Sun et al., 2016). Therefore, it is of great significance to understand and reveal the trends and possible climate change impacts of extreme climate events.

The increasing frequency of extreme climate events has caused severe socioeconomic losses, which has garnered widespread attention (Zhang et al., 2008; Farajzadeh et al., 2015; Ruml et al., 2017). Many previous studies mainly focused on the extreme circumstances of climate change, including the causes, intensity and frequency. For example, Jiang et al. (2019b) investigated the trends of extreme 
precipitation indices (EPIs) for the period of 1969-2016 in the Wei River Basin (WRB). The results found that El Niño-Southern Oscillation (ENSO) exerted great impacts on the extreme precipitation events. Liu et al. (2018) analyzed the spatial-temporal change patterns of maximum and minimum temperature in the WRB. The results found that solar activity and large-scale atmospheric circulation have stronger influences on annual Tmin than annual Tmax. Tong et al. (2019) found that extreme temperature indices (ETIs) have significantly increased but the EPIs did not show significant changes in the Inner Mongolia.

Previous studies mainly investigated the spatiotemporal changes of extreme climate indices and obtained some results (Menang, 2017; Xiao et al., 2017; Agnihotri et al., 2018). However, few studies focused on the extreme climate events especially extreme temperature events in the WRB, which is the largest tributary of the Yellow River of China (Liu et al., 2017). Based on observed daily temperature data, this paper assessed the spatial and temporal variability of extreme temperature events using fourteen ETIs for the period of 1969-2016 in the WRB. The principal component analysis (PCA), Pearson's correlation, wavelet coherence and phase difference were used to explore the linear and nonlinear relationships between ETIs and typical large-scale global climate anomalies. This paper is organized as follows: material and methods are provided in the Section 2, followed by results and discussion in the Section 3, and conclusions in the Section 4.

\section{Material and methods}

\section{Study area}

The WRB is located between $33.68^{\circ} \mathrm{N}-37.39^{\circ} \mathrm{N}$ latitude and $103.94^{\circ} \mathrm{W}-110.03^{\circ} \mathrm{W}$ longitude, with basin area nearly $135,000 \mathrm{~km}^{2}$. It originates from Gansu province, and flows through Ningxia Hui autonomous region and Shaanxi province from west to east, with length of $818 \mathrm{~km}$, as shown in Figure 1. It can be divided into five sub-basins including the upstream, midstream and downstream of the WRB, Jing River Basin (JRB) and Beiluo River Basin (BRB). The upstream of WRB rises from the Qin Mountains with a length of $430 \mathrm{~km}$. The midstream flows from Linjiacun to Xiwanyang, with length about $180 \mathrm{~km}$. The downstream flows into the Yellow River from Xianyang, with length about $208 \mathrm{~km}$. The JRB originates in the eastern foot of Liupan Mountain (Jiang et al., 2019b).

Due to the diversity of geological, geographical and climatic conditions, the climate of the WRB has obvious seasonal characteristics (Zou et al., 2017). The average temperature in summer is about $25^{\circ} \mathrm{C}$, and below $0^{\circ} \mathrm{C}$ in winter. The WRB is a grain production and important economic zone in the northwest of China, especially after the establishment of Guanzhong-Tianshui Economic Zone (Chang et al., 2015). However, the climate of the WRB varied from region to region, and many extreme climate events happened in the history (Jiang et al., 2013, 2015).

\section{Climate data}

Daily temperature data from 34 meteorological stations that were downloaded from China Meteorological Administration (http://data.cma.cn/), covering the period from January $1^{\text {st }}, 1969$ to December $31^{\text {st }}, 2016$, were used to calculate the ETIs. The temperature data have passed strict quality control, the missing data and unreasonable 
data were carefully checked. The standard deviation exceeding 3 times was defined as the out-of-bound value, compared with the records of adjacent stations through manual inspection, reasonable reservation and unreasonable treatment according to absence. Two anomalies including Niño 3.4 and SOI were used as ENSO indices. The Niño 3.4 data was downloaded from Earth System Research Laboratory of National Oceanic and Atmospheric Administration (NOAA) at http://www.esrl.noaa.gov/. The SOI was downloaded from website at https://crudata.uea.ac.uk/cru/data/soi/.

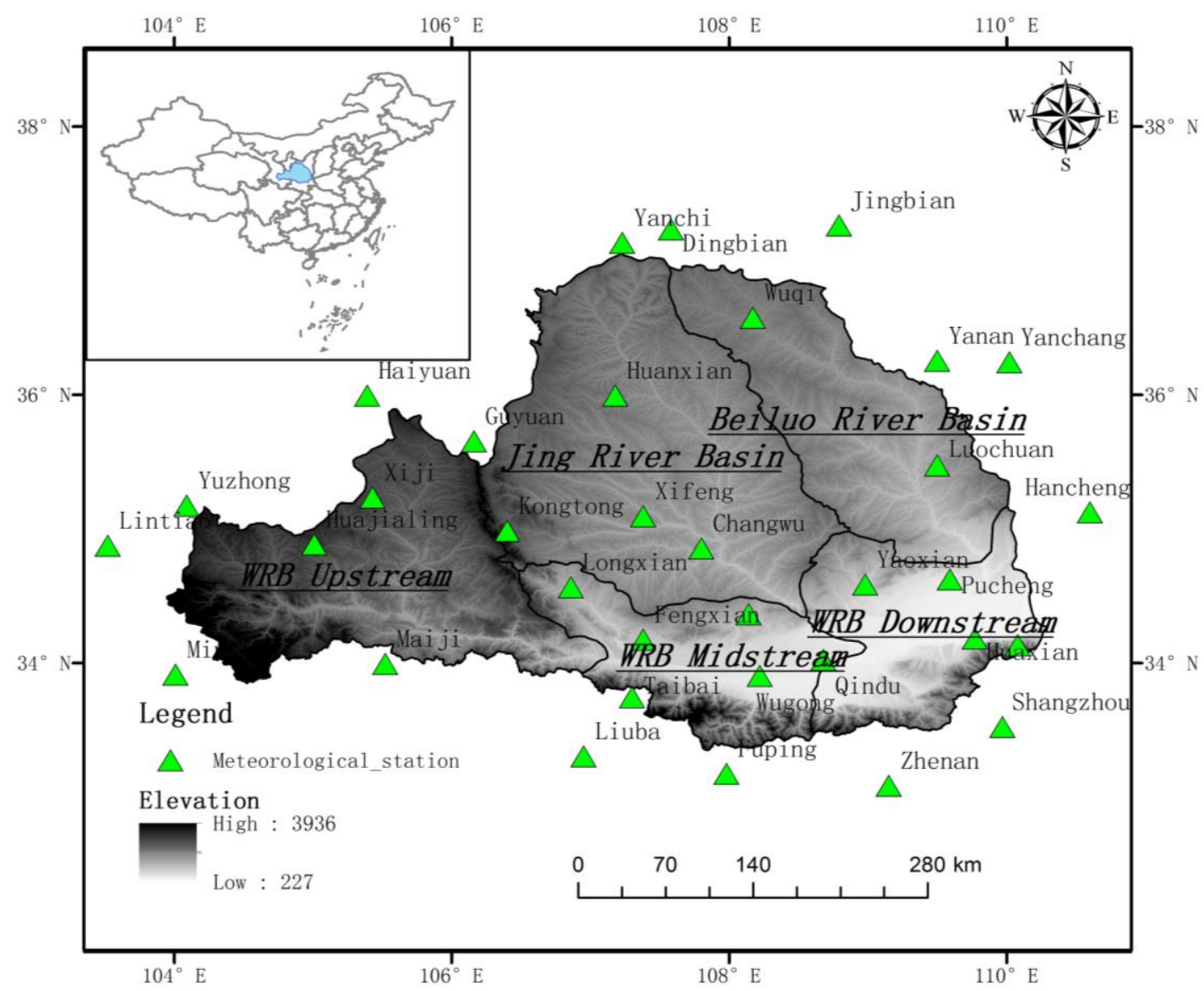

Figure 1. Locations of the WRB and meteorological stations

\section{Definition and calculation of ETIs}

Fourteen ETIs were defined to identify the extreme temperature events in this paper. The details of ETIs are shown in Table 1. These indices identify the changes of temperature in different aspects including intensity, duration and percentile, which have been widely used in previous studies (Popov et al., 2018; Jiang et al., 2017; Sun et al., 2018; Jiang et al., 2019a). A R based software named RClimDex was used to calculated the ETIs. RClimDex was based on a powerful and freely available statistical package $\mathrm{R}$ which runs under both Windows and Unix/Linux. It has a friendly graphical user interface and provides simple quality control process on the input daily temperature data, which has been widely used after it was developed (Almazroui et al., 2014; Jiang et al., 2018). More details of extreme climate indices and RClimDex can refer to the website at http://etccdi.pacificclimate.org/software.shtml. 
Table 1. Details of 14 ETIs used in the study

\begin{tabular}{|c|c|c|c|}
\hline Acronym & ETIs & Definitions & Units \\
\hline FD0 & Frost days & Annual count when daily minimum $(\mathrm{TN})<0^{\circ} \mathrm{C}$ & Days \\
\hline SU25 & Summer days & Annual count when daily maximum $(\mathrm{TX})>25^{\circ} \mathrm{C}$ & Days \\
\hline ID0 & Ice days & Annual count when $\mathrm{TX}<0^{\circ} \mathrm{C}$ & Days \\
\hline GSL & $\begin{array}{l}\text { Growing season } \\
\text { Length }\end{array}$ & $\begin{array}{c}\text { Annual count between first span of at least } 6 \text { days with } \\
\text { daily mean temperature (TG) }>5^{\circ} \mathrm{C} \text { and first span after } \\
\text { July } 1 \text { of } 6 \text { days with } \mathrm{TG}<5^{\circ} \mathrm{C}\end{array}$ & Days \\
\hline TN10p & Cool nights & Percentage of days when $\mathrm{TN}<10$ th percentile & $\%$ of Days \\
\hline TX10p & Cool days & Percentage of days when $\mathrm{TX}<10$ th percentile & $\%$ of Days \\
\hline TN90p & Warm nights & Percentage of days when $\mathrm{TN}>90$ th percentile & $\%$ of Days \\
\hline TX90p & Warm days & Percentage of days when TX > 90th percentile & $\%$ of Days \\
\hline WSDI & $\begin{array}{c}\text { Warm spell duration } \\
\text { indicator }\end{array}$ & $\begin{array}{c}\text { Annual count of days with at least } 6 \text { consecutive days } \\
\text { when TX }>90 \text { th percentile }\end{array}$ & Days \\
\hline CSDI & $\begin{array}{c}\text { Cold spell duration } \\
\text { indicator }\end{array}$ & $\begin{array}{c}\text { Annual count of days with at least } 6 \text { consecutive days } \\
\text { when TN }<10 \text { th percentile }\end{array}$ & Days \\
\hline DTR & $\begin{array}{c}\text { Diurnal temperature } \\
\text { range }\end{array}$ & Monthly mean difference between TX and TN & ${ }^{\circ} \mathrm{C}$ \\
\hline TR20 & Tropical nights & Annual count when $\mathrm{TN}>20^{\circ} \mathrm{C}$ & Days \\
\hline Tmax & $\begin{array}{l}\text { Annual maximum } \\
\text { temperature }\end{array}$ & Annual maximum temperature & ${ }^{\circ} \mathrm{C}$ \\
\hline Tmin & $\begin{array}{l}\text { Annual minimum } \\
\text { temperature }\end{array}$ & Annual minimum temperature & ${ }^{\circ} \mathrm{C}$ \\
\hline
\end{tabular}

\section{Research methodology}

\section{Non-parametric Mann-Kendall test}

The non-parametric Mann-Kendall test, recommended by the World Meteorological Organization, which has been widely used to estimate the trends of time series, was used to examine the trends of the ETIs (Mann, 1945; Kendall, 1975; Du et al., 2015).

For a data series $X=\left\{x_{1}, x_{2}, \ldots, x_{n}\right\}$, the statistic $S$ is calculated by Equation 1 .

$$
S=\sum_{i=1}^{n-1} \sum_{j=i+1}^{n} \operatorname{sgn}\left(x_{j}-x_{i}\right)
$$

where

$$
\operatorname{sgn}\left(x_{j}-x_{i}\right)=\left\{\begin{array}{l}
1, x_{j}-x_{i}>0 \\
0, x_{j}-x_{i}=0 \\
-1, x_{j}-x_{i}<0
\end{array}\right.
$$

The variance $V$ is calculated using by Equation 3 .

$$
V=\frac{n(n-1)(2 n+5)}{18}
$$


where $n$ is the length of the data sequences, and Mann-Kendall' $Z$ is calculated by Equation 4.

$$
Z=\left\{\begin{array}{l}
(S-1) / \sqrt{V}, S>0 \\
0, S=0 \\
(S-1) / \sqrt{V}, S<0
\end{array}\right.
$$

The value of $Z$ indicates the trend of series. $Z>0$ means positive trend, and vice versa for $Z<0$. Two significance levels including $1 \%$ and $5 \%$ were used to detect the statistically significant trends of ETIs.

\section{Wavelet coherence and phase difference}

Wavelet coherence (WTC) can be used to measure the part of local correlation between two data series in time and frequency domain. The wavelet transform of data series $X$ and $Y$ were $W_{n}^{X}(S)$ and $W_{n}^{Y}(S)$. The wavelet coherence defined by Torrence and Webster was given as follows:

$$
R_{n}^{2}(s)=\frac{\left|S\left\langle s^{-1} W_{n}^{X Y}(s)\right\rangle\right|^{2}}{S\left\langle s^{-1}\left|W_{n}^{X}(s)\right|^{2}\right\rangle S\left\langle s^{-1}\left|W_{n}^{Y}(s)\right|^{2}\right\rangle}
$$

where $R_{n}^{2}(s) \in[0,1]$, and $W_{n}^{X Y}(s)=W_{n}^{X}(s) \times W_{n}^{Y}(s)$.

The smoothing operator $S$ of $W_{n}^{X Y}(s)$ in numerator and wavelet power spectrum in denominator is given as follows:

$$
\begin{gathered}
S(W)=S_{\text {scale }}\left(S_{\text {time }}(W(s, t))\right) \\
\left.S(W)\right|_{s}=\left.\left(W(t, s) c_{1} e^{-\left(t^{2} / 2 s^{2}\right)}\right)\right|_{s} \\
\left.S(W)\right|_{n}=\left.\left(W(t, s) c_{2} \Pi(0.6 s)\right)\right|_{n}
\end{gathered}
$$

where $S_{\text {scale }}$ indicates smoothing along the wavelet scale axis and $S_{\text {time }}$ denotes smoothing in time, $C_{1}$ and $C_{2}$ are the normalized constants, $\Pi$ is the rectangle function. The wavelet phase difference is given as follows:

$$
\phi_{n}(s)=\tan ^{-1}\left(\mathfrak{J}\left\{\left\langle s^{-1} W_{n}^{X Y}(s)\right\rangle\right\} / \mathfrak{R}\left\{\left\langle s^{-1} W_{n}^{X Y}(s)\right\rangle\right\}\right)
$$

where $\mathfrak{T}\{\ldots\}$ and $\mathfrak{R}\{\ldots\}$ are the imaginary and real part of wavelet spectra, respectively. More details of WTC can be found at previous studies (Torrence and Compo, 1998; Grinsted et al., 2004). 


\section{Normal Cloud model}

The cloud model is mainly used to reveal the uncertain transformation between qualitative concept and quantitative instance (Li et al., 2009; Qin et al., 2011; Wang et al., 2014). It has been widely used in many fields such as data mining, pattern recognition. (Li et al., 1998; Grecu and Krajewski, 2000; Zhou et al., 2015). The cloud model uses three indicators to represent its characteristics: 1) Expectation (Ex), is the expectation of cloud droplets in domain space division, 2) Entropy (En), is a measure of qualitative concept uncertainty, which is determined by the randomness and fuzziness of concepts, 3) Hyper-Entropy (He), is the entropy of entropy. More details of normal cloud model can be found in previous studies (Li et al., 2009; Qin et al., 2011).

Let $U$ be the universe of discourse and $\tilde{A}$ be a qualitative concept in $U$. If $x \in U$ is a random instantiation of concept $\tilde{A}$, which satisfies $x \sim N\left(E x, E n^{2}\right)$, $E n^{\prime} \sim N\left(E n, H e^{2}\right)$, and the certainty degree of $x$ belong to concept $\tilde{A}$ satisfies.

$$
y=e^{-\frac{(x-E x)^{2}}{2\left(E n^{\prime}\right)^{2}}}
$$

Then the distribution of $x$ in the universe $U$ is called as a normal cloud.

\section{Principal component analysis}

As a frequently-used statistical method, the PCA obtain different orthogonal principal components by reducing the dimension of multivariate data series, and explain most of the variability of original data series through a certain number of principal components. The leading principal component (PC1) was used as a substitution for each ETIs (Singh, 2006; Jiang et al., 2014).

\section{Results and discussion}

\section{Change patterns of ETIs in the WRB}

Trends of each ETIs were analyzed using non-parametric Mann-Kendall test. The trends were classified into seven categories including positive, statistically significant positive ( $5 \%$ \& $1 \%)$, stationary, negative, statistically significant negative (5\% \& 1\%), to provide more knowledge of the change characteristics of the ETIs.

The trends of 14 ETIs are shown in Table 2, which demonstrate the proportions of positive, stationary and negative trends of 14 ETIs in 34 stations, respectively.

Figure 2 shows the spatial distributions of trends in 14 ETIs for 34 meteorological stations for the period of 1969-2016 in the WRB. All fourteen ETIs except DTR were significantly increasing trends dominated. Eight ETIs including Tmax, Tmin, SU25, TR20, TN90P, TX90P, WSDI and GSL showed increasing trends for most of the stations. Other six ETIs showed decreasing trends. 
Table 2. Trends of 14 ETIs (\%)

\begin{tabular}{c|c|c|c|c|c|c|c}
\hline ETIs & Positive trend & SS (5\%) & SS (1\%) & Negative trend & SS (5\%) & SS (1\%) & Stationary trend \\
\hline Tmax & $94.12 \%$ & $17.65 \%$ & $5.88 \%$ & $5.88 \%$ & $0.00 \%$ & $0.00 \%$ & $0.00 \%$ \\
Tmin & $82.35 \%$ & $2.94 \%$ & $14.71 \%$ & $17.65 \%$ & $0.00 \%$ & $0.00 \%$ & $0.00 \%$ \\
FD0 & $0.00 \%$ & $0.00 \%$ & $0.00 \%$ & $100.00 \%$ & $2.94 \%$ & $91.18 \%$ & $0.00 \%$ \\
ID0 & $0.00 \%$ & $0.00 \%$ & $0.00 \%$ & $100.00 \%$ & $38.24 \%$ & $47.06 \%$ & $0.00 \%$ \\
SU25 & $100.00 \%$ & $32.35 \%$ & $50.00 \%$ & $0.00 \%$ & $0.00 \%$ & $0.00 \%$ & $0.00 \%$ \\
TR20 & $91.18 \%$ & $17.65 \%$ & $38.24 \%$ & $2.94 \%$ & $0.00 \%$ & $0.00 \%$ & $5.88 \%$ \\
TN10P & $2.94 \%$ & $0.00 \%$ & $0.00 \%$ & $94.12 \%$ & $2.94 \%$ & $88.24 \%$ & $0.00 \%$ \\
TX10P & $0.00 \%$ & $0.00 \%$ & $0.00 \%$ & $100.00 \%$ & $8.82 \%$ & $91.18 \%$ & $0.00 \%$ \\
TN90P & $100.00 \%$ & $5.88 \%$ & $94.12 \%$ & $0.00 \%$ & $0.00 \%$ & $0.00 \%$ & $0.00 \%$ \\
TX90P & $100.00 \%$ & $17.65 \%$ & $79.41 \%$ & $0.00 \%$ & $0.00 \%$ & $0.00 \%$ & $0.00 \%$ \\
WSDI & $100.00 \%$ & $5.88 \%$ & $0.00 \%$ & $0.00 \%$ & $0.00 \%$ & $0.00 \%$ & $0.00 \%$ \\
CSDI & $2.94 \%$ & $0.00 \%$ & $0.00 \%$ & $94.12 \%$ & $14.71 \%$ & $0.00 \%$ & $2.94 \%$ \\
DTR & $47.06 \%$ & $5.88 \%$ & $8.82 \%$ & $52.94 \%$ & $0.00 \%$ & $14.71 \%$ & $0.00 \%$ \\
GSL & $100.00 \%$ & $11.76 \%$ & $79.41 \%$ & $0.00 \%$ & $0.00 \%$ & $0.00 \%$ & $0.00 \%$ \\
\hline
\end{tabular}

*SS denote statistically significant trends at $5 \%$ or $1 \%$, respectively

Among 34 stations, only Changwu and Yanchi station showed downward trends in Tmax, which are located at the north and south of the JRB, respectively. Other stations showed upward trends. Three stations including Fengxiang and Wugong stations in the WRB midstream, and Luochuan station in the middle of the BRB, had significant increasing trends. Compared with Tmax, six stations had decreasing trends in Tmin. The trends of FD0 and ID0 in 34 stations were similar, with mainly downward trends dominated, and more than $90 \%$ of the stations had statistically significant decreasing trends at 5\% significance level for FD0. Compared with the upward trends of SU25 for all stations, one station showed decreasing trend and two stations showed stationary trends for TR20. It is worth noting that TR20 in Minxian and Huajialing were all stationary. TX10P and TN10P showed downward trends for almost 34 stations. However, TX90P and TN90P showed upward trends. The trends of WSDI and CSDI were mainly opposite. The CSDI showed upward trends in all stations, but only several stations were statistically significant at 5\% significance level for the period of 19692016.

\section{Spatial distributions of Tmax and Tmin}

In this study, the natural neighborhood method was used to interpolate three primary numerical characteristics in the WRB, and details are shown in Figure 3. Generally, three numerical characteristics have obvious and irregular spatial distributions. Figure $3 a$ shows that the Tmax ranges from $25.29^{\circ} \mathrm{C}$ to $39.08^{\circ} \mathrm{C}$, and the western WRB is lower than other regions. Figure $3 b$ shows that the Tmin ranges from $-23.50^{\circ} \mathrm{C}$ to $-8.53^{\circ} \mathrm{C}$, but the northern WRB is lower than that in the Guanzhong Plain. Figure $3 c$ shows that the entropy values in the north and centre of the WRB are lower than those in the south and west, which indicates that the change in the north is more stable. Figure $3 d$ show that the change of Tmin entropy is greater than the annual maximum. It can be concluded that the change of Tmin is more stable in the south-central region near the Qinling Mountains, but it is unstable in the north. 

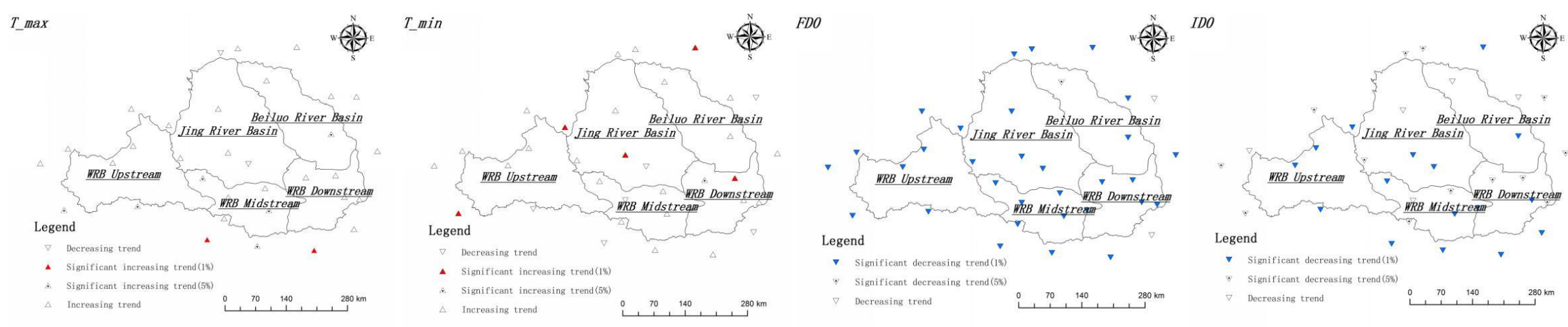

SU25
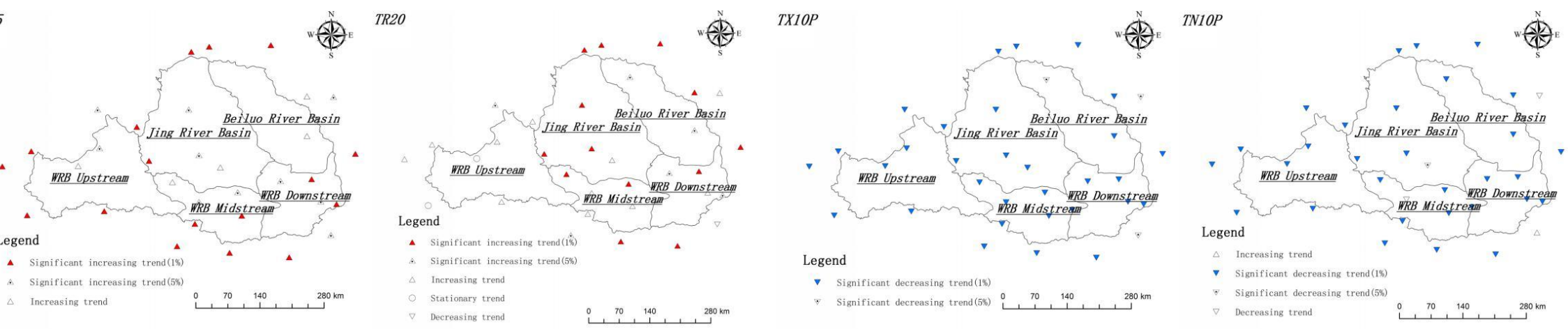

APPLIED ECOLOGY AND ENVIRONMENTAL RESEARCH 18(2):2395-2412.

http://www.aloki.hu • ISSN 15891623 (Print) • ISSN 17850037 (Online)

DOI: http://dx.doi.org/10.15666/aeer/1802_23952412

(c) 2020, ALÖKI Kft., Budapest, Hungary 
TN9OP

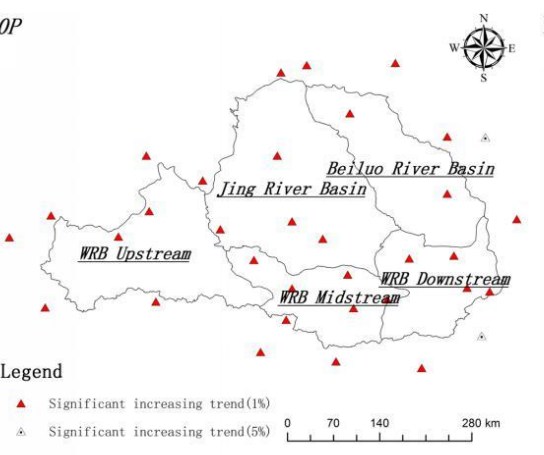

TX90P

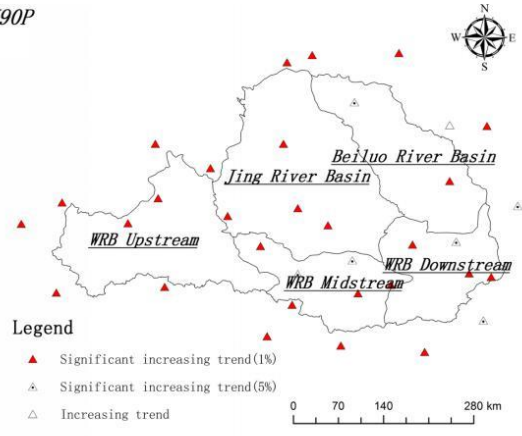

$\operatorname{CSDI}$
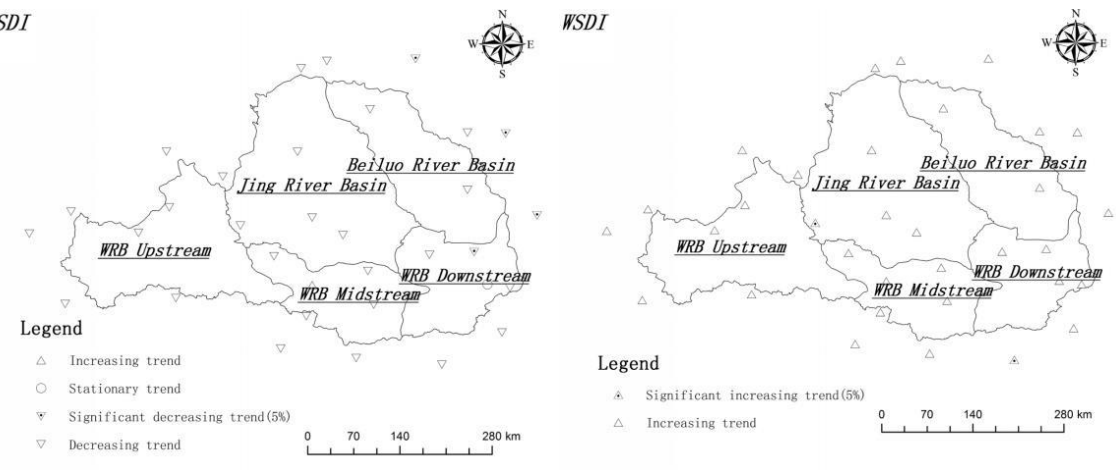

DTR
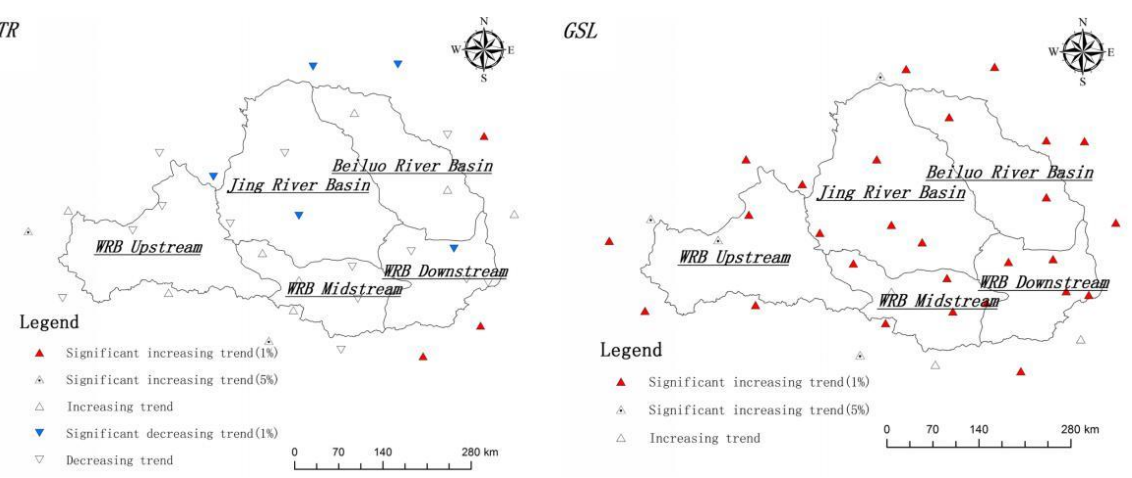

Figure 2. Spatial distributions of trends of 14 ETIs: (a)Tmax, (b)Tmin, (c)FDO, (d)IDO, (e)SU25, (f)TR20, (g)TN1OP, (h)TX10P, (i)TN90P, (j)TX90P, (k)CSDI, (l)WSDI, (m)DTR, (n)GSL 

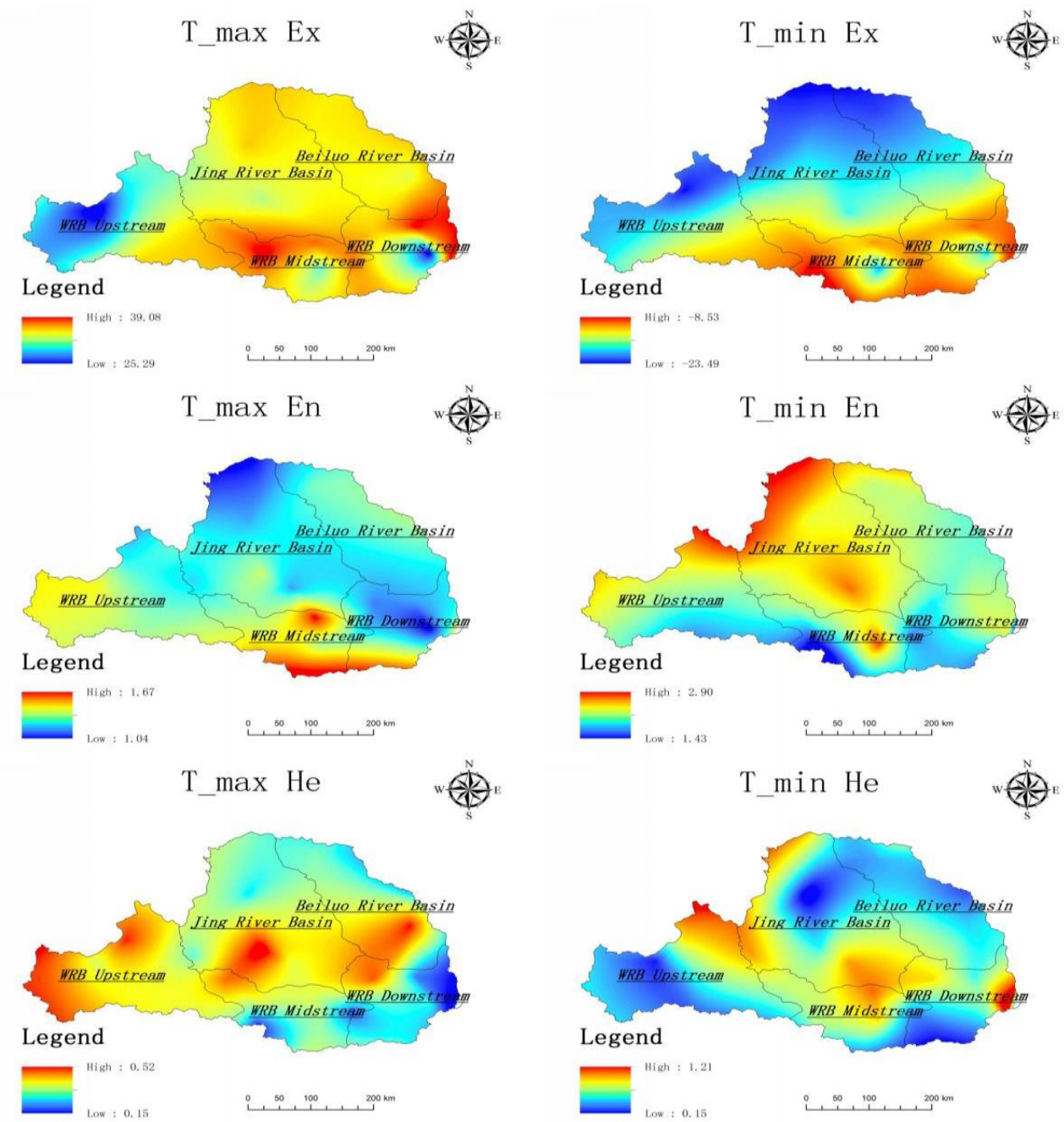

Figure 3. Spatial distributions of three numerical characteristics in the WRB. (a)Ex of Tmax, (b)Ex of Tmin, (c)En of Tmax, (d)En of Tmin, (e)He of Tmax, (f)He of Tmin

Ex indicates average values of Tmax and Tmin. En is used to react the instability of Tmax and Tmin sequences. The entropy value of Tmin is larger than that of Tmax, which indicates that the Tmin in the WRB is more unstable and scattered than that of Tmax. The standard deviations of them are calculated to further verify that the Tmin series is more uneven and unstable.

He represents the dispersion of entropy, and the larger the hyper entropy, the more the instability. Similar with entropy, the super entropy of Tmin is larger than that of Tmax, which indicates that the Tmin is more nonuniform the Tmax. In general, the Tmin variation has higher dispersion and instability than the Tmax variation in the WRB. Guanzhong Plain is the main grain production area in Shaanxi province. Annual minimum temperature changes have a negative impact on grain production. Therefore, the local government should scientifically prevent and adopt appropriate strategies to deal with this phenomenon.

The results show that generally the ETIs have similar trends for different stations, which are increasing trends dominated, as shown in Table 2 and Figure 2. The cold extreme indices such as FD0 and ID0 have significant negative trends, and the warm 
extreme indices have significant positive trends. Changes in these indices indicate that extreme temperature events had mainly increased from 1969 to 2016, which is mainly consistent with previous results. For example, Zhou et al. (2011) founded that the numbers of frost days and ice days were significantly reduced in mainland China. Shi et al. (2018) found that the TR20, SU25, TX90P and TN90P had increased, but the FD0, ID0, TX10P and TN10P had decreased. The results showed that Tmax and Tmin of the JRB located in the Loess Plateau, have higher instability compared with other areas of the WRB. The results are consistent with Liu et al. (2018) who explored the maximum and minimum temperature variation in the WRB. The results found that solar activity and large-scale atmospheric circulation have stronger influences on annual Tmin than annual Tmax.

\section{Correlation between ETIs and typical climate anomalies}

PCA was used to extract the PC1 of each ETIs before correlation analysis between ETIs and two typical large-scale global climate anomalies including Niño 3.4 and SOI, because the PC1 of each ETIs represented the largest proportion of total variability.

Table 3 shows the correlation coefficients between each ETIs. The results show that PC1 of FD0 was negatively correlated with TN90P $(\rho=-0.87)$. FD0 showed decreasing trends in 34 stations, but TN90P showed increasing trends. Thus, PC1 of FD0 and TN90P showed negative correlation. It is worth noting that there has positive correlations between typical warm temperature extremes including TX90P, TN90P, SU25, TR20 and WSDI. Similarly, there has positive correlations between typical cold temperature extremes including TN10P, TX10P, FD0, ID0 and CSDI, indicating that the warm ETIs are generally correlated with the cold ETIs. DTR and GSL also have positive correlations with warm ETIs and negative correlations with cold ETIs, except that the DTR is positively correlated with TN10P.

Table 3. Cross correlation coefficients between different ETIS

\begin{tabular}{|c|c|c|c|c|c|c|c|c|c|c|c|c|c|c|}
\hline ETIs & FD0 & ID0 & TMAX & TMIN & SU25 & TR20 & TN10P & TX10P & TN90P & TX90P & WSDI & CSDI & DTR & GSL \\
\hline FD0 & 1 & $0.42 *$ & -0.11 & -0.15 & $-0.55^{*}$ & $-0.45^{*}$ & $0.77 *$ & $0.63^{*}$ & $-0.87 *$ & $-0.64 *$ & $-0.39 *$ & $0.31^{*}$ & -0.35 & $-0.85^{*}$ \\
\hline ID0 & & 1 & -0.19 & $-0.46^{*}$ & $-0.30 *$ & $-0.32 *$ & $0.60 *$ & $0.68 *$ & $-0.49 *$ & $-0.51 *$ & $-0.40 *$ & $0.48^{*}$ & $-0.38 *$ & $-0.35 *$ \\
\hline TMAX & & & 1 & 0.25 & $0.47 *$ & $0.44 *$ & $-0.16^{*}$ & $-0.45^{*}$ & $0.37 *$ & $0.40^{*}$ & $0.35^{*}$ & -0.18 & $0.39 *$ & 0.14 \\
\hline TMIN & & & & 1 & 0.22 & 0.13 & -0.27 & $-0.37 *$ & 0.25 & $0.29 *$ & 0.26 & $-0.43^{*}$ & 0.24 & 0.12 \\
\hline SU25 & & & & & 1 & $0.56^{*}$ & $-0.45^{*}$ & $-0.66^{*}$ & $0.67 *$ & $0.76^{*}$ & $0.51 *$ & -0.28 & $0.60 *$ & $0.50 *$ \\
\hline TR20 & & & & & & 1 & $-0.61 *$ & $-0.57 *$ & $0.62 *$ & $0.48^{*}$ & $0.33^{*}$ & $-0.30 *$ & 0.19 & $0.43 *$ \\
\hline TN10P & & & & & & & 1 & $0.70^{*}$ & $-0.74 *$ & $-0.46^{*}$ & -0.25 & $0.63^{*}$ & 0.07 & $-0.64 *$ \\
\hline TX10P & & & & & & & & 1 & $-0.65^{*}$ & $-0.54 *$ & $-0.35^{*}$ & $0.50^{*}$ & $-0.46^{*}$ & $-0.61 *$ \\
\hline TN90P & & & & & & & & & 1 & $0.81 *$ & $0.48 *$ & $-0.33^{*}$ & 0.19 & $0.77 *$ \\
\hline TX90P & & & & & & & & & & 1 & $0.77 *$ & -0.28 & $0.62 *$ & $0.66^{*}$ \\
\hline WSDI & & & & & & & & & & & 1 & -0.13 & $0.51 *$ & $0.33 *$ \\
\hline CSDI & & & & & & & & & & & & 1 & -0.18 & $-0.35^{*}$ \\
\hline DTR & & & & & & & & & & & & & 1 & 0.24 \\
\hline GSL & & & & & & & & & & & & & & 1 \\
\hline
\end{tabular}

- $\quad$ indicates statistically significant at $5 \%$ significant level 
Figure 4 shows the correlation coefficients between ETIs and Niño 3.4, SOI. In general, all cold ETIs except TN10P are negatively correlated with Niño 3.4 and positively correlated with SOI, and all warm ETIs are positively correlated with SOI and negatively correlated with Niño 3.4, except TN90P, which indicated that Niño 3.4 had negative impacts on the cold EITs and positive impacts on the warm ETIs, and vice versa for SOI. Among the cold ETIs, $\rho$ between ID0 and two typical climate anomalies was the strongest. In case of the warm ETIs, TX90P and WSDI was more strongly correlated with Niño 3.4 and SOI than other ETIs. Therefore, four ETIs including TN10P, TX10P, TN90P and TX90P were selected to analysis the nonlinear relationships between Niño 3.4 and SOI using wavelet analysis in the following section.

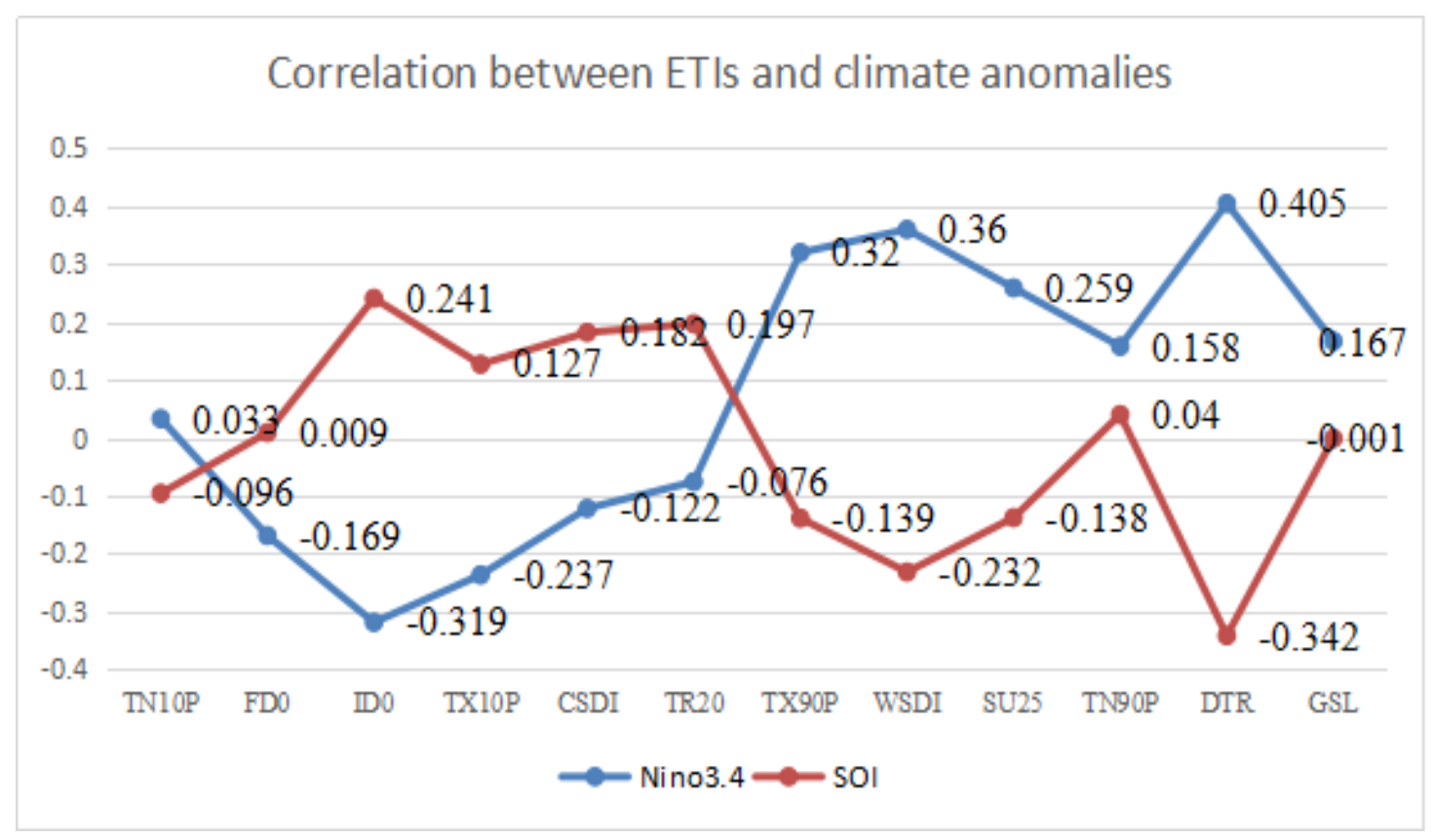

Figure 4. Pearson's correlation coefficients between ETIs and Niño 3.4, SOI

\section{Wavelet analysis between ETIs and SOI}

Figure $5 a$ shows the wavelet coherence and phase difference between SOI and PC1 of TN10P. The results show that there is a 0-3 years cycle during 1969-1975 with negative correlations, a 2-4 years cycle after 2005 with a $-90^{\circ}$ phase difference and an 8-12 years cycle during 1970-1988 with a $45^{\circ}$ phase difference. A 3 year cycle during 1995-2000 with a $-90^{\circ}$ phase difference and a 6 years cycle during 1994-1996 with negative correlations are also detected. Figure $5 b$ shows wavelet coherence and phase difference between SOI and PC1 of TX10P. The results indicate that there is a 0-4 years cycle during 1995-2000, and the coherence was in-phase dominated. Figure 5c shows the wavelet coherence and phase difference between SOI and PC1 of TN90P. There is a 2-4 years cycle during 1990-2000, and the phase difference was $45^{\circ}$. The WTC analysis between SOI and PC1 of TX90P is shown in Figure 5d. There have a 3-6 years cycle during 1969-2016 and a 0-3 years cycle during 1985-1990, both of the coherence were dominated by anti-phase. 

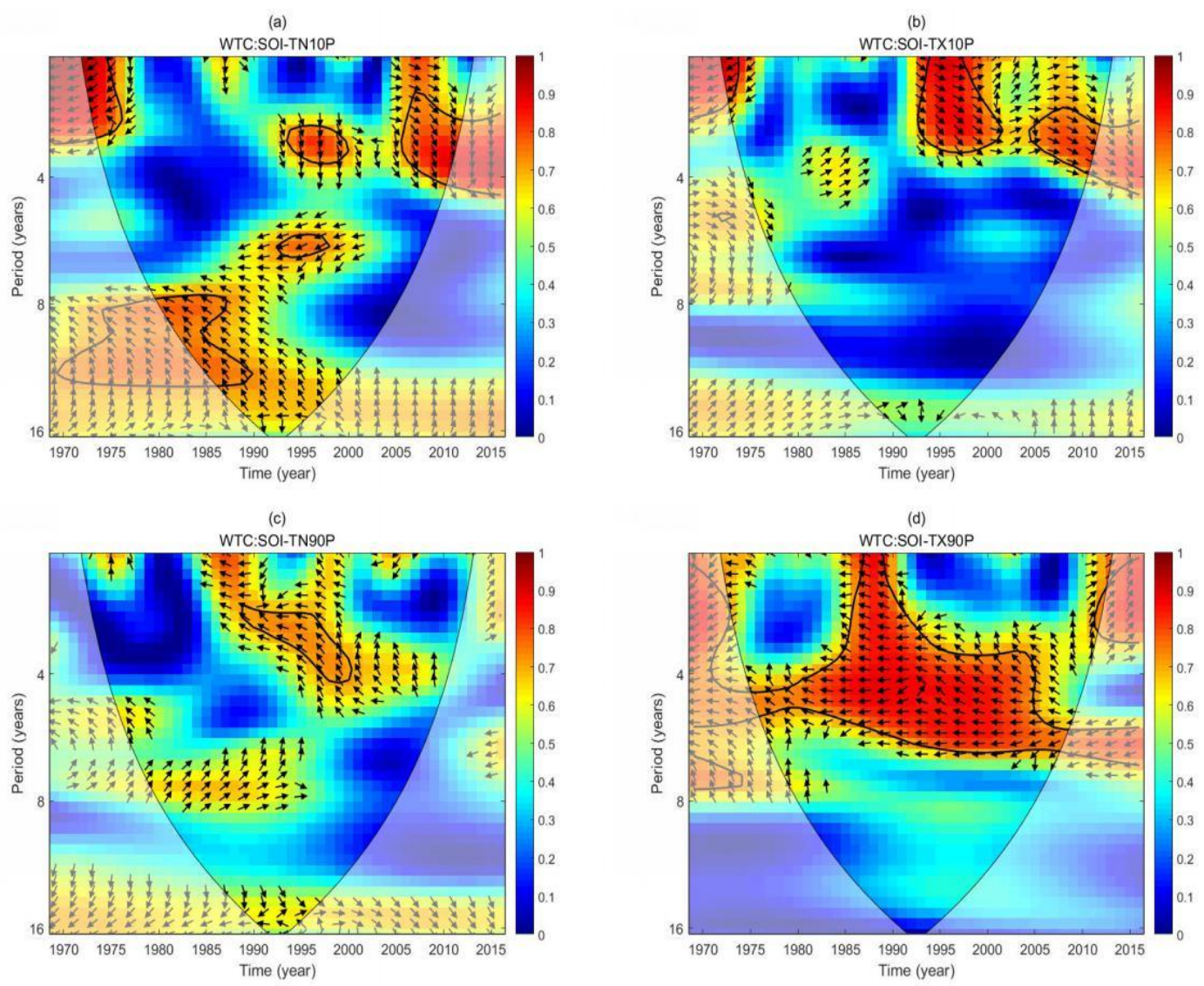

Figure 5. WTC between SOI and PC1 of typical ETIs: (a)TN1OP, (b)TX10P, (c)TN90P, (d)TX90P during 1969-2016

\section{Wavelet analysis between ETIs and Niño 3.4}

Figure $6 a$ shows the wavelet coherence and phase difference between Niño 3.4 and PC1 of TN10P. The results show that PC1 of TN10P is positively correlated with Niño 3.4, with a signal of 6-7 years during 1993-2003 and a 0-3 years signal during 1969-1977, it is noteworthy that half of the area are outside the cone of influence (COI), which need to be interpreted in cautious. The results also show that the Niño 3.4 leads PC1 of TN10P a quarter cycle, with a signal of 3 years during 1995-2000 and a 0-4 years signal during 2005-2016. The results also show the Niño 3.4 lags PC1 of TN10P a quarter cycle with a 12 years signal during 1970-1988, but most of the area are outside the COI. Figure $6 b$ shows the wavelet coherence and phase difference between Niño 3.4 and PC1 of TX10P. There has a 2-year cycle during 1995-2000, and the phase difference was $45^{\circ}$. There are also statistically significant negative correlations with a 4 years cycle during 1983-1985. Figure $6 c$ shows the wavelet coherence and phase difference between Niño 3.4 and PC1 of TN90P. There has a 4-year cycle during 1999-2005, and the phase difference was $-90^{\circ}$. The WTC analysis between Niño 3.4 and PC1 of TX90P is shown in Figure 6d. The results show that PC1 of TX90P is positively correlated with Niño 3.4, with a signal of 4-6 years during 1980-2005 and a 0-4 years cycle during 1988-1990.

To reveal the change mechanism and potential influencing factors of ETIs in the WRB, we further investigate the teleconnections between typical ETIs and climate 
anomalies including Niño 3.4 and SOI. The results show that the correlation between ETIs and global climate anomalies is intricate, which vary in both time and frequency. However, the results of correlation between PC1 of ETIs and Niño 3.4, SOI (as shown in Figure 4) are consistent with the phase difference in Figure 5 and Figure 6. Take TN10P and TX10p for examples, we found that the PC1 of TN10P and SOI are negatively correlated in Figure 4, and their phase differences are anti-phase, similarly, TX10P and SOI are positively correlated with each other and their phase differences are in-phase. The teleconnections between ETIs and ENSO indicated that the extreme temperature events might be predicted using large-scale climate anomalies as potential predictors. Previous studies have shown that the negative correlation between rainfall and SOI in the Loess Plateau is significant on the high time-frequency scale (Wang et al., 2019). However, the effects of atmospheric circulation patterns on regional temperature have been studied by many previous studies, such as Pacific Decadal Oscillation (PDO) (Newman et al., 2016; Zhang et al., 2018; Geng et al., 2019), Pacific/ North American (PNA) (Ning and Bradley, 2016), North Atlantic Oscillation (NAO) (Pokorna and Huth, 2015; Wang et al., 2017) and Arctic Oscillation (AO) (Otomi et al., 2013; Park and Ahn, 2016). Therefore, it should be better to include more global climate anomalies to predict the extreme temperature events based on their strong relationships (Loikith and Broccoli, 2012; Grotjahn et al., 2016).
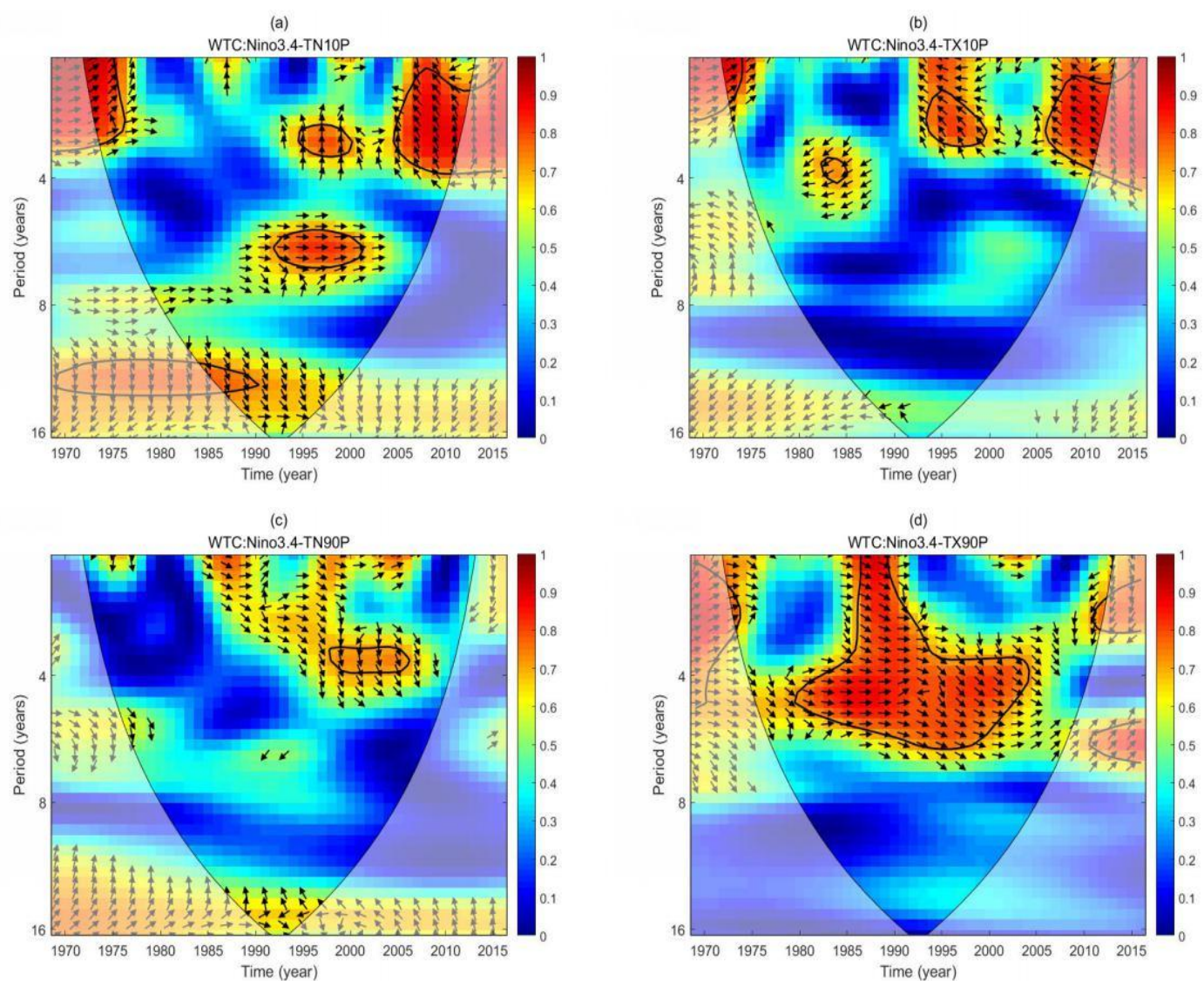

Figure 6. WTC between Niño 3.4 and PC1 of typical ETIs: (a)TN1OP, (b)TX10P, (c)TN90P, (d)TX90P during 1969-2016 


\section{Conclusions}

In this paper, fourteen ETIs were used to evaluate the extreme temperature events. The temporal and spatial variability of ETIs were analyzed using non-parametric Mann-Kendall test method during 1969-2016 in the WRB. To reveal the potential relationships between extreme temperature change and atmospheric circulation factors, Niño 3.4 and SOI were used to investigated their linear and nonlinear relationships with ETIs. The main conclusions are summarized as follows:

In general, ETIs exhibited similar variability for different stations. Eight ETIs including Tmax, Tmin, SU25, TR20, TN90P, TX90P, WSDI and GSL showed mainly increasing trends, and five ETIs including FD0, ID0, TN10P, TX10P and CSDI showed mainly negative trends. Using cloud model of Tmax and Tmin, the results showed that the geographical location has an important influence on the spatial variability of $E n, E x$ and He. Tmax, Tmin and Ex in the middle and lower reaches are higher than the JRB and BRB, which might be caused by the rapid urbanization of Guanzhong Plain and the urban heat island effect. $\mathrm{En}$ and $\mathrm{He}$ in the middle reaches are higher, which indicates that the Guanzhong Plain is more uneven and stable than other regions, which may be due to the influence of human activities and the difference of solar activities in different regions.

Two climate anomalies including Niño 3.4 and SOI had similar wavelet coherence and phase difference with PC1 of four ETIs. The inter-decadal oscillation between Niño 3.4 (SOI) and TN10P was found at about 12 years cycle. The results of phase difference between ETIs and SOI, Niño 3.4 are mainly opposite, positive with SOI, and negative with Niño 3.4, which are consistent with the results of Pearson's correlation (Figure 4). It is noteworthy that the oscillations between ETIs and climate anomalies need to be interpreted in cautious because of the limited data series.

The results of this study provide a reliable estimation of extreme temperature events, which provide references for water resource management and climate planning in the WRB. In particular, the potential impacts between large-scale climate anomalies and extreme temperature events provide some scientific basis and ideas for using large-scale climate anomalies to estimate the occurrence of regional extreme temperature events. The future work will focus on the prediction of extreme climate events using multiple global climate anomalies.

Acknowledgements. This study was partly supported by National Key Research and Development Program of China (2016YFC0401408), National Natural Science Foundation of China (51679188, 51509201 and 51979221), Natural Science Basic Research Plan in Shaanxi Province of China (Grant No. 2018JM5031). Daily temperature data can be downloaded from the China Meteorological Administration at http://data.cma.cn/. The SOI data can be downloaded from https://crudata.uea.ac.uk/cru/data/soi/. ENSO data were obtained from the Earth System Research Laboratory of NOAA, which can be downloaded from https://www.esrl.noaa.gov/psd/data/correlation/nina34.data/. RClimDex used to calculate the ETIs can be downloaded at http://etccdi.pacificclimate.org/software.shtml.

\section{REFERENCES}

[1] Agnihotri, I., Punia, M. P., Sharma, J. R. (2018): Assessment of spatial variations in temperature and precipitation extremes in west-flowing river basin of Kutch, Saurashtra and Marwar, India. - Current Science 114(2): 322-328. 
[2] Almazroui, M., Islam, M. N., Dambul, R., Jones, P. D. (2014): Trends of temperature extremes in Saudi Arabia. - International Journal of Climatology 34: 808-826.

[3] Chang, J. X., Wang, Y. M., Istanbulluoglu, E., Bai, T., Huang, Q., Yang, D. W., Huang, S. Z. (2015): Impact of climate change and human activities on runoff in the Weihe River Basin, China. - Quaternary International 380: 169-179.

[4] Du, S. Q., Gu, H. H., Wen, J. H., Chen, K., Van Rompaey, A. (2015): Detecting Flood Variations in Shanghai over 1949-2009 with Mann-Kendall Tests and a NewspaperBased Database. - Water-Sui 7(5): 1808-1824.

[5] Farajzadeh, M., Oji, R., Cannon, A. J., Ghavidel, Y., Bavani, A. M. (2015): An evaluation of single-site statistical downscaling techniques in terms of indices of climate extremes for the Midwest of Iran. - Theoretical and Applied Climatology 120(1-2): 377390.

[6] Geng, T., Yang, Y., Wu, L. X. (2019): On the Mechanisms of Pacific Decadal Oscillation Modulation in a Warming Climate. - Journal of Climate 32(5): 1443-1459.

[7] Grecu, M., Krajewski, W. F. (2000): Rainfall forecasting using variational assimilation of radar data in numerical cloud models. - Advances in Water Resources 24(2): 213-224.

[8] Grinsted, A., Moore, J. C., Jevrejeva, S. (2004): Application of the cross wavelet transform and wavelet coherence to geophysical time series. - Nonlinear Processes in Geophysics 11: 561-566.

[9] Grotjahn, R., Black, R., Leung, R., Wehner, M. F., Barlow, M., Bosilovich, M., Gershunov, A., Gutowski, W. J., Gyakum, J. R., Katz, R. W., Lee, Y.-Y., Lim, Y.-K., Prabhat (2016): North American extreme temperature events and related large scale meteorological patterns: a review of statistical methods, dynamics, modeling, and trends. - Climate Dynamics 46(3-4): 1151-1184.

[10] Huang, S. Z., Chang, J. X., Huang, Q., Chen, Y. T. (2014): Spatio-temporal Changes and Frequency Analysis of Drought in the Wei River Basin, China. - Water Resources Management 28(10): 3095-3110.

[11] Huang, S. Z., Hou, B. B., Chang, J. X., Huang, Q., Chen, Y. T. (2015): Spatial-temporal change in precipitation patterns based on the cloud model across the Wei River Basin, China. - Theoretical and Applied Climatology 120(1-2): 391-401.

[12] Intergovernmental Panel on Climate Change (IPCC). (2014): Climate Change 2014: Synthesis Report. - Contribution of Working Groups I, II and III to the Fifth Assessment Report of the Intergovernmental Panel on Climate Change. IPCC: Geneva, Switzerland.

[13] Jiang, R. G., Xie, J. C., Li, J. X. (2013): Application of World Wind on hydrologic monitoring and simulation in Shaanxi province, China. - Disaster Advances 6: 33-47.

[14] Jiang, R. G., Gan, T. Y., Xie, J. C., Wang, N. (2014): Spatiotemporal variability of Alberta's seasonal precipitation, their teleconnection with large-scale climate anomalies and sea surface temperature. - International Journal of Climatology 34(9): 2899-2917.

[15] Jiang, R. G., Xie, J. C., He, H. L., Luo, J. G., Zhu, J. W. (2015): Use of four drought indices for evaluating drought characteristics under climate change in Shaanxi, China: 1951-2012. - Natural Hazards 75(3): 2885-2903.

[16] Jiang, R. G., Xie J. C., Zhao Y., He H. L., He G. H. (2017): Spatiotemporal variability of extreme precipitation in Shaanxi province under climate change. -Theoretical and Applied Climatology, 130, 831-845.

[17] Jiang, R. G., Yu, X., Xie, J. C., Zhao, Y., Li, F. W., Yang, M. X. (2018): Recent changes in daily climate extremes in a serious water shortage metropolitan region, a case study in Jing-Jin-Ji of China. - Theoretical and Applied Climatology 134: 565-584.

[18] Jiang, R. G., Wang Y. P., Xie J. C., Zhao Y., Li F. W, Wang X. J. (2019a): Multiscale characteristics of Jing-Jin-Ji's seasonal precipitation and their teleconnection with largescale climate indices. - Theoretical and Applied Climatology 137(1-2):1495-1513.

[19] Jiang, R. G., Wang, Y. P., Xie, J. C., Zhao, Y., Li, F. W., Wang, X. J. (2019b): Assessment of extreme precipitation events and their teleconnections to El Nino Southern 
Oscillation, a case study in the Wei River Basin of China. - Atmospheric Research 218: 372-384.

[20] Kendall, M. G. (1975): Rank Correlation Measures. - Charles Griffin: London, UK.

[21] Li, D. Y., Han, J. W., Shi, X. M., Chung Chan, M. (1998): Knowledge representation and discovery based on linguistic atoms. - Knowledge-Based Systems 10(7): 431-440.

[22] Li, D. Y., Liu, C. Y., Gan, W. Y. (2009): A New Cognitive Model: Cloud Model. International Journal of Intelligent Systems 24(3): 357-375.

[23] Liu, S. Y., Huang, S. Z., Huang, Q., Xie, Y. Y., Leng, G. Y., Luan, J. K., Song, X. Y., Wei, X., Li, X. Y. (2017): Identification of the non-stationarity of extreme precipitation events and correlations with large-scale ocean-atmospheric circulation patterns: A case study in the Wei River Basin, China. - Journal of Hydrology 548: 184-195.

[24] Liu, S. Y., Huang, S. Z., Xie, Y. Y., Huang, Q., Leng, G. Y., Hou, B. B., Zhang, Y., Wei, X. (2018): Spatial-temporal changes of maximum and minimum temperatures in the Wei River Basin, China: Changing patterns, causes and implications. - Atmospheric Research 204: 1-11.

[25] Loikith, P. C., Broccoli, A. J. (2012): Characteristics of Observed Atmospheric Circulation Patterns Associated with Temperature Extremes over North America. Journal of Climate 25(20): 7266-7281.

[26] Mann, H. B. (1945): Non-parametric test against trend. - Econometrica 13: 245-259.

[27] Menang, K. P. (2017): Climate extreme indices derived from observed daily precipitation and temperature data over Cameroon: the need for further assessments. - Meteorological Applications 24(2): 167-171.

[28] Newman, M., Alexander, M. A., Ault, T. R., Cobb, K. M., Deser, C., Di Lorenzo, E., Mantua, N. J., Miller, A. J., Minobe, S., Nakamura, H., Schneider, N., Vimont, D. J., Phillips, A. S., Scott, J. D., Smith, C. A. (2016): The Pacific Decadal Oscillation, Revisited. - Journal of Climate 29(12): 4399-4427.

[29] Ning, L., Bradley, R. S. (2016): NAO and PNA influences on winter temperature and precipitation over the eastern United States in CMIP5 GCMs. - Climate Dynamics 46(34): $1257-1276$.

[30] Otomi, Y., Tachibana, Y., Nakamura, T. (2013): A possible cause of the AO polarity reversal from winter to summer in 2010 and its relation to hemispheric extreme summer weather. - Climate Dynamics 40(7-8): 1939-1947.

[31] Park, H. J., Ahn, J. B. (2016): Combined effect of the Arctic Oscillation and the Western Pacific pattern on East Asia winter temperature. - Climate Dynamics 46(9-10): 32053221.

[32] Pokorna, L., Huth, R. (2015): Climate impacts of the NAO are sensitive to how the NAO is defined. - Theoretical and Applied Climatology 119(3-4): 639-652.

[33] Popov, T., Gnjato, S., Trbic, G., Ivanisevic, M. (2018): Recent Trends in Extreme Temperature Indices in Bosnia and Herzegovina. - Carpathian Journal of Earth and Environmental Sciences 13(1): 211-224.

[34] Qin, K., Xu, K., Liu, F. L., Li, D. Y. (2011): Image segmentation based on histogram analysis utilizing the cloud model. - Computer \& Mathematics with Applications 62(7): 2824-2833.

[35] Ruml, M., Gregoric, E., Vujadinovic, M., Radovanovic, S., Matovic, G., Vukovic, A., Pacuca, V., Stojfcic, D. (2017): Observed changes of temperature extremes in Serbia over the period 1961-2010. - Atmospheric Research 183: 26-41.

[36] Shi, J., Cui, L. L., Ma, Y., Du, H. Q., Wen, K. M. (2018): Trends in temperature extremes and their association with circulation patterns in China during 1961-2015. - Atmospheric Research 212: 259-272.

[37] Singh, C. V. (2006): Pattern characteristics of Indian monsoon rainfall using principal component analysis (PCA). - Atmospheric Research 79(3): 317-326. 
[38] Sun, W. Y., Mu, X. M., Song, X. Y., Wu, D., Cheng, A. F., Qiu, B. (2016): Changes in extreme temperature and precipitation events in the Loess Plateau (China) during 19602013 under global warming. - Atmospheric Research 168: 33-48.

[39] Sun, P., Zhang, Q., Yao, R., Singh, V. P., Song, C. Q. (2018): Spatiotemporal Patterns of Extreme Temperature across the Huai River Basin, China, during 1961-2014, and Regional Responses to Global Changes. - Sustainability 10(4): 1-21.

[40] Tong, S. Q., Li, X. Q., Zhang, J. Q., Bao, Y. H., Bao, Y. B., Na, L., Si, A. L. (2019): Spatial and temporal variability in extreme temperature and precipitation events in Inner Mongolia (China) during 1960-2017. - Science of the Total Environment 649: 75-89.

[41] Torrence, C., Compo, G. P. (1998): A practical guide to wavelet analysis. - Bulletin of the American Meteorological Society 79: 61-78.

[42] Utsumi, N., Seto, S., Kanae, S., Maeda, E. E., Oki, T. (2011): Does higher surface temperature intensify extreme precipitation? - Geophysical Research Letter 38.

[43] Wang, G. Y., Xu, C. L., Li, D. Y. (2014): Generic normal cloud model. - Information Sciences 280: 1-15.

[44] Wang, X. F., Li, J. P., Sun, C., Liu, T. (2017): NAO and its relationship with the Northern Hemisphere mean surface temperature in CMIP5 simulations. - Journal of Geophysical Research-Atmosphere 122(8): 4202-4227.

[45] Wang, X. H., Wang, B. T., Xu, X. Y. (2019): Effects of large-scale climate anomalies on trends in seasonal precipitation over the Loess Plateau of China from 1961 to 2016. Ecol Indic 2019: 107.

[46] Xiao, M. Z., Zhang, Q., Singh, V. P. (2017): Spatiotemporal variations of extreme precipitation regimes during 1961-2010 and possible teleconnections with climate indices across China. - International Journal of Climatology 37(1): 468-479.

[47] Zhang, F., Gao, H., Cui, X. (2008): Frequency of extreme high temperature days in China, 1961-2003. - Weather 63(2): 46-49.

[48] Zhang, Y., Xie, S. P., Kosaka, Y., Yang, J. C. (2018): Pacific Decadal Oscillation: Tropical Pacific Forcing versus Internal Variability. - Journal of Climate 31(20): 82658279.

[49] Zhou, Y. Q., Ren, G. Y. (2011): Change in extreme temperature event frequency over mainland China, 1961-2008. - Climate Research 50(2-3): 125-139.

[50] Zhou, Q., Wang, W., Pang, Y., Zhou, Z. Y., Luo, H. P. (2015): Temporal and spatial distribution characteristics of water resources in Guangdong Province based on a cloud model. - Water Science and Engineering 8(4): 263-272.

[51] Zou, L., Xia, J., She, D. X. (2017): Drought Characteristic Analysis Based on an Improved PDSI in the Wei River Basin of China. - Water 9(3): 178. 